\title{
Study to assess the prevalence of antiphospholipid syndrome (APS) among women with adverse pregnancy outcome in a tertiary care centre
}

\author{
Ajitha Ravindran R K ${ }^{1}$, Jayshree V Vaman ${ }^{2}$, Nirmala $C^{3}$, Sujatha T L $^{4}$, Geetha M I \\ ${ }^{1}$ Dr Ajitha Ravindran R K, Assistant Professor, Department of Obstetrics and Gynaecology, ${ }^{2}$ Dr Jayshree V Vaman, \\ Additional Professor, Department of Obstetrics and Gynaecology, ${ }^{3}$ Dr Nirmala C, Professor, Department of Obstetrics and \\ Gynaecology, ${ }^{4}$ Dr Sujatha T L, Additional Professor, Department of Obstetrics and Gynaecology, ${ }^{5}$ Dr Geetha M I, Additional \\ Professor, Department of Obstetrics and Gynaecology, all authors are attached with Government Medical College \\ Trivandrum, Kerala, India.
}

Address for Correspondence: Dr Ajitha Ravindran R K, Assistant Professor, Department of Obstetrics and Gynaecology Government Medical College Trivandrum. E-mail id: ajitharoy7@gmail.com

\begin{abstract}
Introduction: Antiphospholipid syndrome is an autoimmune condition characterized by vascular thrombosis and/or pregnancy morbidity in the presence of antiphospholipid antibodies. A failure or significant delay in recognizing APS as the underlying disease entity may leave to the loss of an opportunity to prevent serious consequences of the disease particularly venous and arterial thrombotic events. Aim of the Study: To find out the prevalence of antiphospholipid syndromeamong women with adverse pregnancy outcome in a tertiary care centre. Methodology: Patients registered in O \&G Department SAT Hospital, Medical College, Trivandrum, Kerala with adverse pregnancy outcomes meeting the inclusion and exclusion criteria were recruited for the study. They were followed up in the postnatal ward after abortion and preterm delivery as per protocol for bad obstetrics outcome evaluation. They were offered lab test in standard labs for APL Syndrome especially LAC and anti-cardiolipin antibodies IgM \& IgG. Those tested positive were retested 12 weeks later also to confirm the test. Results: In the present study, out of 216 cases of patients with adverse pregnancy outcome, 27 cases were found to be APLA positive giving a prevalence of $12.5 \%$. In APLA positive cases LAC \& ACLA were found to be positive in 11 cases each i. e $40.7 \%$ and in 5 cases both LAC \& ACLA were positive i.e. $18.6 \%$. Conclusion: The important message is that even if a patient who is suspected clinically of APS does not fully satisfy the strict classification criteria, she may still have APS and require appropriate management including anticoagulation.
\end{abstract}

Keywords: Antiphospholipid Syndrome, Adverse Pregnancy Outcome

\section{Introduction}

Graham Hughes [1] one of the key figures in the discovery of APS quoted that APS was one of the two "new" diseases of late $20^{\text {th }}$ century, the other being AIDS. Antiphospholipid antibodies were first described by Conley in 1950's when some patients with lupus were noted to have prolonged APTT. The 2005 International Consensus statement on the classification criteria for definite APS recognized anti-B ${ }_{2}$ glycoprotein I- (anti- B2GPI), along with LA and a CL, as pertinent, diagnostic autoantibody in APS However, the standardization and clinical performance characteristics of the currently available assays for anti- $\mathrm{B}_{2}$-GPI anti bodies are still under investigation [2]. Combination of LAC and high levels of ACLA is strongly associated with decidual vasculopathy,

Manuscript received: $24^{\text {th }}$ May 2016

Reviewed: $4^{\text {th }}$ June 2016

Author Corrected: $14^{\text {th }}$ June 2016

Accepted for Publication: $30^{\text {th }}$ June 2016 placental infarction, IUGR, early onset Pre-Eclampsia and recurrent foetal death.

International consensus statements on preliminary criteria for the classification of APS [3]

\section{Clinical Criteria}

1. Vascular thrombosis-One or more clinical episodes of arterial, venous or small vessel thrombosis in any tissue or organ.

\section{Pregnancy morbidity}

i. One or more unexplained deaths of a morphologically normal foetus at or beyond $10^{\text {th }}$ week of gestation, with normal morphology documented by ultrasound or by direct examination of foetus. 


\section{Original Research Article}

ii. One or more premature births of a morphologically normal neonate before $34^{\text {th }}$ week because of (a) eclampsia or severe preeclampsia or (b) recognized features of placental insufficiency.

iii. Three or more unexplained consecutive spontaneous abortions before $10^{\text {th }}$ week of gestation with maternal, anatomic or hormonal and chromosomal causes excluded.

\section{Lab criteria}

1. Anticardiolipin antibodies of $\operatorname{IgM}$ and or $\operatorname{IgM}$ isotype in blood present in medium or high titre on 2 or more occasions at least 12 weeks apart measured by standard ELISA for Beta2 glycoprotein I-dependent anticardiolipin antibodies.

2. Anti-beta 2-glycoprotein I antibodies- aCL antibodies of $\operatorname{IgM}$ or IgM present in medium or high titre on 2 or more occasions at least 12 weeks apart measured by ELISA for betaglycoprteins I antibodies.
3. LA antibodies measured on 2 or more occasions 12 weeks apart.

Patients with APS must manifest at least one of the 2 clinical criteria and one of the 2 lab criteria.

\section{Laboratory Testing}

Patients suspected of having APS should be tested using at least two aPL assays for several reasons. First, there is no definitive association between any of the clinical manifestations of APS and a particular aPL antibody.

Second, there is substantial interlaboratory variation in assay performance and interpretation Currently, the most commonly performed aPL antibody assays are for lupus anti-coagulant and anticardiolipin antibodies (IgM and IgM isotypes) [4]. These are also the most commonly detected aPL antibodies and the only two currently recognized by the 1999 International Consensus Statement.

\section{Materials \& Methods}

Design of Study: Descriptive cross sectional study. Setting: Department of Obstetrics \& Gynaecology, SAT Hospital Medical College, Thiruvananthapuram. Duration of the Study: one year. Study Population The patients who registered in Obstetrics \& Gynaecology department, SAT Hospital, Medical College, Thiruvananthapuram with adverse pregnancy outcomes are recruited for the study. A past history of pregnancy loss was accepted if the diagnosis of pregnancy was confirmed by positive pregnancy tests, ultra sound scans or on histology. The inclusion \& exclusion criteria of adverse pregnancy outcome are as follows Inclusion Criteria: Patients with 2 or more first trimester miscarriages, patients with one or more second trimester miscarriages and those with pregnancy losses less than 34 weeks due to severe Pre-eclampsia, IUGR, abruption and unexplained intra uterine death. Exclusion Criteria: Congenital malformations of foetuses excluded by gross morphological appearance, USG examination or histopathology. Hormonal causes like diabetes, thyroid diseases, anatomical causes and cervical incompetence in the mother are excluded by USG.

Method of Study: Those who fulfil the selection criteria are recruited for the study. They are followed up in the postnatal ward after abortion or preterm delivery. After informed consent, data are collected by a pre-structured interview schedule combined with hospital documents and available lab tests. Detailed information regarding socio-demographic factors, previous pregnancy losses-their gestational age, documentation of fetal heart, any congenital anomalies, complications during antenatal period like severe Pre-eclampsia, IUGR and abruption remote from term, weight of foetuses and investigation results were collected.

Also detailed history regarding past history of Hypertension, Gestational diabetes, hypo-thyroidism, SLE, nephritic syndrome, cardiac disease, personal history of thrombosis like DVT, pulmonary embolism, family history of thrombosis, history of drugs, contraception, addiction, smoking was also taken.

These patients were subjected as per the protocol for bad obstetric outcome evaluation. The patients in our study group were offered laboratory tests in standard labs with expert quality assurance services for APLA syndrome especially lupus anticoagulant assay and anti- cardiolipin IgM \& IgM. Those who were tested positive were retested 12 weeks later also to confirm the test. They were done in the same laboratory to help in standardization of results.

The sample size proposed for the study is calculated from the formula $n=\left(Z^{2} \times p x q\right) / d^{2}$ where $Z x=1.96, p=$ prevalence form the pilot study $=10, q=(100-p)=90$. When $d$ (margin of sampling error) is taken as 4 , the sample size was calculated to be 216. Dates regarding various study variables are collected from all these patients by a pre-structured interview schedule and analysed using statistical package Excel/SPSS.

The significance of findings was tested and data interpreted. 


\section{Observation \& Results}

Table- 1: Distribution of patients according to early or late miscarriages.

\begin{tabular}{|c|c|c|c|c|c|}
\hline & \multicolumn{5}{|c|}{ APLA } \\
\hline & \multicolumn{3}{|c|}{ Positive } & \multicolumn{2}{|c|}{ Negative } \\
\hline & No & $\%$ & No & $\%$ & Total \\
\hline Less than 10 weeks & 14 & 12.0 & 103 & 88.0 & 117 \\
\hline 10-24 weeks & 13 & 16.0 & 68 & 84.0 & 81 \\
\hline
\end{tabular}

In the study group of 117 patients with history of abortions less than 10 weeks, 14 patients were APLA +ve [12\%],

Of 81 patients with history of late miscarriages between 10-24 weeks, 13 patients were APLA +ve [16\%]

Table- 2: Distribution of pregnancy wastage before and after the appearance of foetal heart.

\begin{tabular}{|c|c|c|c|c|c|}
\hline \multirow{2}{*}{ Foetal hearts } & \multicolumn{4}{|c|}{ APLA } \\
\cline { 2 - 7 } & \multicolumn{2}{|c|}{ Positive } & Negative & Total \\
\hline & No & $\mathbf{2 2 . 7}$ & 58 & 77.3 & 75 \\
\hline Present & 17 & $\mathbf{3 . 3}$ & 58 & 96.7 & 60 \\
\hline Absent & 2 & 14.1 & 116 & 85.9 & 135 \\
\hline Total & 19 & &
\end{tabular}

$\mathrm{X} 2=10.303 \quad \mathrm{df}=1 \quad \mathrm{p}=0.001$

Pregnancy wastage occurred in $22.7 \%$ of APLA + ve cases following appearance of foetal cardiac activity. Whereas pregnancy wastage occurred only in $3.3 \%$ of APLA positive cases where the cardiac activity was absent in the beginning itself and the difference was found to be statistically significant.

Table- 3: Prevalence of APLA in the study population.

\begin{tabular}{|c|c|c|}
\hline Category & Frequency & Percent \\
\hline APLA Positive & 27 & $\mathbf{1 2 . 5}$ \\
\hline APLA Negative & 189 & 87.5 \\
\hline Total & $\mathbf{2 1 6}$ & $\mathbf{1 0 0 . 0}$ \\
\hline
\end{tabular}

In the present study out of 216 cases of patients with adverse pregnancy outcome, 27 cases were found to be APLA positive giving a prevalence of $12.5 \%$. The $95 \%$ confidence limits are $8.4 \%$ to $17.6 \%$.

Table- 4: Distribution of LAC \& ACLA in APLA positive cases.

\begin{tabular}{|c|c|c|}
\hline $\begin{array}{c}\text { Lab values Positive cases among the APLA } \\
\text { cases (N=27) }\end{array}$ & Frequency & Percent \\
\hline LAC & 11 & 40.7 \\
\hline ACLA & 11 & 40.7 \\
\hline Both LAC and ACLA & 5 & 18.6 \\
\hline Total & $\mathbf{2 7}$ & $\mathbf{1 0 0}$ \\
\hline
\end{tabular}

In APLA positive cases, Lupus Anticoagulant [LAC] was positive in 11 cases ie. 40.7\% and Anticardiolipin Antibody [ACLA] was positive in 11 cases $40.7 \%$. Both LAC \& ACLA were positive in 5 cases i.e. $18.6 \%$.

\section{Discussion}

In the present study out of those pregnancy losses less than 10 weeks, $12 \%$ were APLA positive and in those between $10-24$ weeks $16 \%$ were APLA positive. [table-1] Out of those with fetal cardiac activity present, $22.7 \%$ were APLA positive. [table2] More recent work by Yetman et al 1996 focusing on women with recurrent pre embryonic pregnancy losses. i.e. losses less than 10 weeks gestation has shown that $10-20 \%$ of these women have detectable APLA [5]. According to Oshiro and coworker [6]1996, Roque and colleagues 2001 [7] fetal deaths are more characteristic than in first trimester miscarriages. The association between APLA and fetal losses is strongest for losses after more than 10 weeks of gestation. 
In the present study of 216 cases with adverse pregnancy outcomes, 27 cases were found to be APLA positive giving a prevalence of $12.5 \%$. The $95 \%$ confidence limits are $8.4 \%$ to $17.6 \%$ [table- 3 ]

In a retrospective review of a cohort of women without SLE by Oshiro and Branch (1996) the prevalence of APLA was $20 \%$ in women with recurrent fetal losses and it was only 5\% in healthy women. In serological evaluation of women with RPL in a study by Kutteh and colleagues [8] 10-20\% have detectable aPL antibodies. In another prospective observational study of 4 years carried out in a teaching hospital in Calcutta, India 2006, the prevalence of APLA was found to be $27.7 \%$ by Ghosh A, Bhattacharya S [9] The prevalence of beta 2-GPI-dependent aCL, LA, and ANA were 3.3, 10.0, and 25.2\%, respectively. Four of the 301 patients had all three antibodies. The LA titres in patients with positive values for three antibodies was significantly higher than in cases with only LA was reported by Ogasawara M et al [10] Another report by Charles et al [11] from London showed a figure between $7 \%$ and $25 \%$ of APS patients.

Comparison of prevalence of APS with other studies.

\begin{tabular}{|l|c|}
\hline \multicolumn{1}{|c|}{ Authors } & Prevalence \\
\hline 1. Oshiro and Branch (4) & $20 \%$ \\
\hline 2. Charles et al (7) & 7 to $25 \%$ \\
\hline 3. Kutteh (5) & 10 to $20 \%$ \\
\hline 4. J.Zolghadri, B.Ghareshi (12) & 17.4 \\
\hline 5. Ghosh A, Bhattacharya , S.M.Calcutta (9) & $27.7 \%$ \\
\hline 6. Present study & $12.5 \%$ \\
\hline
\end{tabular}

In APLA positive cases of present study Lupus Anticoagulant [LAC] was positive in 11 cases ie. 40.7\% and Anticardiolipin Antibody [ACLA] was positive in 11 cases 40.7\%. Both LAC \& ACLA were positive in 5 cases i.e. 18.6\%. [table-4] In the present study considering the type of immunoglobulin of ACLA cases, $87.5 \%$ cases were of IgG type and only $12.5 \%$ were of IgM type Studies by Gharavi and Haris et al [13]. Show that for both ACLA and anti B2 glycoprotein I ab, specifically is highest for IgM isotype and for medium to high titres and IgM isotype is more prevalent in APS patients than isolated IgM.

\section{Recommendations-}

1. Large multi centric collaborative studies are necessary to obtain sufficiently large patient population and hence cohort selection is very important.

2. We have to differentiate women with recurrent early pregnancy losses less than 10 weeks from women who have had late pregnancy losses, preterm delivery less than 34 weeks, severe early onset pre-eclampsia or HELLP syndrome and thus obstetric APS need to be further defined.

3. The diagnosis of this syndrome is challenging. Hence further research on clinically relevant antibodies and standardization of their detection are needed to improve the clinical risk assessment in APS. There are diagnostic challenges faced by the clinicians in diagnosing this disease due to variation of standardization assays. Hence a global screening test should be made available and till then the best screening tool is the history taking.

4. The various anticoagulant regimens and the optimum duration of thromboprophylaxis in obstetric APS should be standardized.

5. Patients diagnosed as APS should be made into APS Registry Entries so that they can be identified easily in any clinical emergency department where they present with different clinical scenario.

\section{Funding: Nil, Conflict of interest: Nil Permission from IRB: Yes}

\section{References}

1. Hughes G. Hughes Syndrome: the antiphospholipid syndrome-a clinical overview. Clin Rev Allergy Immunol. 2007 Feb;32(1):3-12.

2. Clowse ME, Jamison M, Myers E, James AH. A national study of the complications of lupus in pregnancy. Am J Obstet Gynecol. 2008 Aug;199(2):127.e1-6. doi: 10.1016/j.ajog.2008.03.012. Epub 2008 May 5.

3. Miyakis $\mathrm{S}^{1}$, Lockshin $\mathrm{MD}$, Atsumi $\mathrm{T}$, Branch $\mathrm{DW}$, Brey RL, Cervera R, Derksen RH, DE Groot PG, Koike T, Meroni PL, Reber G, Shoenfeld Y, Tincani A, Vlachoyiannopoulos PG, Krilis SA. International consensus statement on an update of the classification criteria for definite antiphospholipid syndrome (APS). J Thromb Haemost. 2006 Feb;4(2):295-306.DOI:10. 1111/j. 1538-7836.2006.01753.x 
Original Research Article

4. Favaloro $\mathrm{EJ}^{1}$, Wong RC. Antiphospholipid antibodies and the antiphospholipid syndrome II: limitations, standardization, and clinical utility of laboratory testing. Semin Thromb Hemost. 2008 Jun; 34(4):309-12. doi: 10.1055/s-0028-1085472. Epub 2008 Sep 23. DOI: $10.1055 / \mathrm{s}-0028-1085472$

5. Yetman DL, Kutteh WH. Antiphospholipid antibody panels and recurrent pregnancy loss: prevalence of anticardiolipin antibodies compared with other antiphospholipid antibodies. Fertil Steril. 1996 Oct; 66 (4):540-6.

6. Oshiro BT, Silver RM, Scott JR, Yu H, Branch DW. Antiphospholipid antibodies and fetal death. Obstet Gynecol. 1996 Apr;87(4):489-93.

7. Roque H, Paidas M, Rebarber A, et al: Maternal thrombophilia is associated with second and third trimester fetal death. Am J Obstet Gynecol 184: S27, 2001.

8. Kutteh WH. Antiphospholipid antibody-associated recurrent pregnancy loss: treatment with heparin and low- dose aspirin is superior to low-dose aspirin alone. Am J Obstet Gynecol. 1996 May;174(5):1584-9.

9. Ghosh A, Ghosh M, Bhattacharya SM. Antiphospholipid antibodies as a cause of recurrent pregnancy loss: a study in Calcutta, India. J Obstet Gynaecol. 2006 Jul;26(5):407-10.

10. Ogasawara M, Aoki K, Katano K, Aoyama T, Kajiura S, Suzumori K. Prevalence of autoantibodies in patients with recurrent miscarriages. Am J Reprod Immunol. 1999 Jan;41(1):86-90.

11 Munther A. Khamastha.E.et al. Antiphospholipid Syndrome. British Medical Journal 314:25,1997.

12. Zolghadri, B.Gharesi. The Prevalence of Antiphospholipid Syndrome in patients with recurrent pregnancy loss: A report from South Iran. MJIRI, Vol.18, No.2,119-121,2004.

13. Gharavi AE, Harris EN, Asherson RA, Hughes GR. Anticardiolipin antibodies: isotype distribution and phospholipid specificity. Ann Rheum Dis. 1987 Jan; 46(1):1-6.

\section{How to cite this article?}

Ajitha Ravindran R K, Jayshree V Vaman, Nirmala C, Sujatha T L, Geetha M I. Study to assess the prevalence of antiphospholipid syndrome (APS) among women with adverse pregnancy outcome in a tertiary care centre. Obs Rev: $J$ obstet Gynecol 2016;2(2):3-7. doi: 10.17511/joog.2016.i02.02. 